\title{
A produção para piano a duas mãos de Alberto Nepomuceno \\ Características gerais e proposta de um novo catálogo
}

Mónica Vermes

O compositor Alberto Nepomuceno (1864-1920), uma das figuras mais importantes e atuantes de sua época na música brasileira, legou-nos um corpus de obras nos mais importantes gêneros, música sacra, canções, música de câmara, ópera, música sinfônica, peças para instrumentos solistas, para formações instrumentais e vocais diversificadas. A sua figura, porém, é mais freqüentemente lembrada como aquela do mais importante precursor da música de caráter nacionalista no Brasil. Apoiando-se nessa premissa, as avaliações de sua obra têm-se debruçado, de modo geral, sobre uma parcela bastante específica de sua produção, parcela essa não necessariamente típica.

Uma aproximação à produção de Nepomuceno para piano a duas mãos (existem também obras para a mão esquerda e reduções para piano a quatro mãos de obras sinfônicas de sua lavra) permite-nos verificar o quanto a abordagem da obra de Nepomuceno exclusivamente sob o ponto de vista "nacionalista", baseia-se numa polarização entre nacional - internacional, que se tem feito sentir de maneira especialmente marcante na música brasileira a partir da década de 1920 e que tem marcado de maneira quase geral a avaliação da música artística brasileira do presente e do passado. 
Nepomuceno apresenta bem os dois aspectos - em sua obra convivem o nacional e o internacional - convidando-nos a reformular nossa abordagem da música romântica brasileira a partir de um ponto de vista que considere a especificidade desse momento na história da música no Brasil.

No presente trabalho apresentamos um panorama geral da produção para piano a duas mãos de Alberto Nepomuceno e uma reformulação do catálogo desse conjunto de suas obras.

Abreviaturas utilizadas:
AN - Alberto Nepomuceno
BN - Biblioteca Nacional
EMB - Enciclopédia da Música Brasileira
MP - Miguel Proença
SNAC - Sérgio Nepomuceno Alvim Corrêa

A escolha desta parcela específica de seu repertório, música para piano a duas mãos, foi determinada em função dos elementos que apresentaremos a seguir. $O$ instrumento musical ao qual Nepomuceno dedicou-se principalmente foi o piano. As primeiras obras por ele compostas foram para esse instrumento, e, apesar de as suas composições para piano sofrerem uma rarefação ao longo de sua vida, podemos encontrar obras compostas para este instrumento em períodos diferentes, permitindo-nos observar o amadurecimento da escrita do compositor e algumas características gerais do seu estilo. Além do citado, o compositor tinha uma ligação afetiva com o instrumento, como pode ser percebido na seguinte passagem, extraída de uma carta de Nepomuceno a seu filho Eivind - que, na ocasião, estudava na Suíça - datada de 25 de novembro de 1907: "Fiquei muito satisfeito por quereres estudar piano. (...) Tem sido esse instrumento o meu ganha-pão, justo será que o ames também pois tens aproveitado dele."

As obras para a mão esquerda só e as reduções de obras orquestrais de sua autoria para piano a quatro mãos, apesar de não 
constituírem um conjunto numeroso, exigiriam ferramentas diferenciadas para sua abordagem e, por esse motivo, não foram consideradas em nosso presente trabalho.

O primeiro passo necessário para abordar o repertório citado foi estabelecer o conjunto das obras a serem consideradas. $\mathrm{O}$ trabalho com diversas fontes, primárias e secundárias, evidenciou a existência de uma série de discrepâncias quanto ao conteúdo preciso do catálogo de obras de Nepomuceno.

Nossa referência básica foi o Catálogo geral da obra de Nepomuceno, elaborado por Sérgio Nepomuceno Alvim Corrêa ${ }^{1}$, o qual foi compatibilizado com o verbete "Alberto Nepomuceno" e o "Registro de Músicas" da Enciclopédia da Música Brasileira", os catálogos das exposições comemorativas do centenário de nascimento de Nepomuceno realizadas na Biblioteca $\mathrm{Nacional}^{3}$ e na Escola Nacional de Música ${ }^{4}$, um esboço de curriculum vitoe do punho do próprio compositor ${ }^{5}$ do qual consta uma lista de suas composições com excertos da crítica e uma segunda lista feita por um membro da família de Nepomuceno ${ }^{6}$, além de consultas ao $\mathrm{Sr}$. Sérgio N. Alvim Corrêa e a artigos de jornal e programas de concerto da época das primeiras audições das obras.

A análise desse material permitiu-nos identificar alguns pontos a retificar no catálogo. Apuramos, por exemplo, que duas obras tratam-se, na verdade, de entradas repetidas de peças já incluídas com outro nome.

Tal é o caso da Berceuse e do Ninna Nanna. Os dois títulos referem-se a uma única peça. Este fato é justificado por encontrarem-se referências à mesma obra ora com um nome, ora com outro. O catálogo de SNAC fornece-nos dados sobre as duas obras que se complementam, por exemplo, data e local de estréia da Berceuse e dados sobre a edição do Ninna Namna, mas não há referências à edição da primeira ou à estréia da segunda. Na EMB aparecem duas informações diferentes, no verbete "Alberto Nepomuceno", a obra é apresentada como berceuse Ninna nanna e no "Registro de Músicas" aparecem as duas obras com entradas 
distintas, ambas datadas de 1890. No catálogo da exposição da BN a obra aparece da seguinte forma: "Nina Nana (Berceuse) para piano (...)". No catálogo manuscrito de AN encontramos uma Berceuse, mas o nome em si dá margem a confusão, pois ninna nanna, em italiano, ou berceuse, em francês, referem-se ambas a uma cantiga de ninar. Na gravação da obra integral para piano de AN por MP encontramos o Ninna Nanna, mas a Berceuse não aparece. Há ainda uma referência a uma Berceuse de AN na "Alocução" de Antônio Salles", onde o autor a identifica com a canção folclórica Jardineiro de meu pai. Essa canção coincide, porém, com o tema de Sesta na Rede, da Série Brasileira para orquestra, que o autor do texto identifica com uma cantiga de ninar, não se tratando portanto de uma berceuse para piano. Interpretamos o fato de a Berceuse aparecer desdobrada no catálogo de SNAC devido ao aparecimento da obra com dois nomes diferentes nos documentos da época: nas críticas dos concertos de Nepomuceno aparece como Berceuse, na edição aparece como Ninna Nanna. Acreditamos que AN tenha utilizado inicialmente o título francês, de acordo com a prática então corrente, e que o título tenha sido vertido ao italiano quando da edição pela casa italiana.

Outras duas peças com as quais se deu o mesmo fato são a Romança em mi bemol e Une Fleur. A Romança aparece no catálogo de SNAC como manuscrito sem edição, mas sem referência a um eventual extravio do mesmo (fato especificado claramente no caso do Scherzo Fantastico). A Romança não consta do catálogo da EMB, nem dos catálogos manuscritos ou das gravações de MP. Acreditamos que esta obra e Une Fleur também se tratem de uma única obra, idéia reforçada em função do subtítulo da segunda obra coincidir com o nome da primeira (Une Fleur - romance), ambas terem sido escritas na mesma época e Une Fleur encontrarse em mi bemol, tonalidade que identifica a Romança. A crítica da época tratou a peça ora por um nome, ora por outro.

Outra obra de existência duvidosa é a Melodia de 1894. Não encontramos nenhuma referência a esta composição, seja grava- 
ção, partitura editada ou manuscrito. A única indicação que temos é aquela do catálogo de SNAC. Esta obra é particularmente passível de causar confusão, devido ao fato de encontrarmos no catálogo de SNAC três obras com o mesmo nome: a Melodia de 1894, a Melodia em lá maior (sem data, manuscrito) e a Melodia em fá menor (sem data, editada postumamente). Na EMB é feita referência a apenas duas Melodias, uma de 1906 e a outra sem data; no catálogo manuscrito de AN há referência a apenas uma Melodia e no catálogo da família há referência a uma Melodia, aparentemente editada por Carlos Wehrs e por Bevilacqua (é importante lembrar, porém, que as informações deste catálogo apresentam várias imprecisões). A peça também não consta das gravações de MP. Consideramos que a inclusão desta peça no catálogo deva-se a alguma confusão com uma das duas outras "melodias" sem data de Nepomuceno.

Outra obra constante do catálogo SNAC e que julgamos não pertencer a este grupo de peças é a Prece, já que se trata de uma transcrição para piano a duas mãos de uma obra originalmente escrita para violoncelo e piano, transcrição essa realizada por Barroso Neto, elaborada e estreada em 1934 (14 anos depois da morte de Nepomuceno), não justificando sua inclusão no catálogo de obras para piano.

De modo semelhante consideramos que A Cigarra, obra composta em 1911 no Rio de Janeiro, não deve ser incluída no catálogo de obras para piano por se tratar de uma redução, não de obra originalmente escrita para piano (nem mesmo consta que a redução tenha sido feita pelo autor). É constituída de quatro peças da opereta A Cigarra, escrita por AN com o pseudônimo de João Valdez.

Uma outra retificação realizada no catálogo diz respeito às tonalidades das duas mazurcas compostas por Nepomuceno. A Mazurka $\mathbf{n}^{0} 1$ aparece no catálogo de SNAC na tonalidade de ré menor, quando na verdade essa tonalidade corresponde à Mazurka opus $8 \mathrm{n}^{\circ} 2$. No manuscrito original a primeira é identificada como opus $1 n^{\circ} 2$, numeração que provavelmente tenha dado origem à troca de tonalidades. 
Outra obra que apresenta dúvidas é a Dança de Negros para piano (esta recebeu o nome de Batuque na Série Brasileira). No catálogo de SNAC consta que a obra tenha sido orquestrada pelo autor em 1891, para fazer parte da Série Brasileira, existindo ainda uma transcrição de J. Octaviano para piano solo. No catálogo manuscrito de $\mathrm{AN}$, esta peça não consta entre as composições para piano e no catálogo da família, ao lado da Série Brasileira, aparece a indicação "piano $\mathrm{x}$ orchestra" e mais adiante aparece Batuque "V. piano". A edição que consta do catálogo de SNAC (Arthur Napoleão \& Cia.) traz escrito em sua primeira página "Reducção para piano do autor", levando-nos a crer que seja uma edição posterior ao aparecimento da Série Brasileira, não havendo notícias do paradeiro de uma primeira versão para piano, seja publicada ou manuscrita. De qualquer modo, a versão para piano já existia em 1888 , fato comprovado por notícia de jornal publicada na Gazeta do Norte de $11 / 5 / 1888^{8}$, que faz referência a ela.

A dedicação de Nepomuceno à composição de obras para piano não foi constante nem homogênea ao longo de sua vida, há períodos de produção mais abundante intercalados com períodos em que essa modalidade é completamente abandonada. É importante notar que de um total de 23 peças escritas para piano a duas mãos, 14 foram escritas até 1895 (com lapsos nos anos de 1888 e 1890). Como foi justamente em 1895 que Nepomuceno voltou da viagem de estudos à Europa, relacionamos então as peças produzidas nesse período com sua fase de formação musical. Outras quatro peças não estão datadas ${ }^{9}$, e as cinco restantes são de: 1901, 1902-1912, 1904 (duas delas) e 1915, caracterizando uma produção bastante esporádica a partir de 1895. Consideramos que muitas das peças escritas entre 1891 e 1895 possam ter sido compostas com fins específicos: exigências de caráter acadêmico ou para efeito de participação de concursos, fato citado em carta de Nepomuceno de 30/05/1890 a Frederico Nascimento:

Nada conclui para o concurso Rubinstein! Tinha que fazer um Concertstück para piano e orquestra, uma suite de pe- 
quenas peças para piano e uma Sonata para piano só, ou piano e violino e violoncelo. Tudo iniciado e não acabado! $A$ razão é que os trabalhos para Berlim, o alemão e um tempozinho perdido com as minhas tonteiras e um cansaço exorbitante (...) não me davam calma e nem repouso para meditar e pensar bem no desenvolvimento de meus trabalhos.

$\mathrm{O}$ autor refere-se provavelmente à Sonata em fá menor e às Peças Líricas.

As primeiras peças para a mão esquerda aparecem em 1906, quando sua filha Sigrid contava oito anos de idade. Essas peças foram compostas especialmente para ela, visto que, devido a um problema de nascença, ela não tinha a mão direita.

Observamos que a composição de peças para canto (em todas as suas modalidades) tem uma homogeneidade muito maior, sofrendo interrupções apenas em 1901 e 1910, períodos em que Nepomuceno viajou à Europa, e em 1905.

Um aspecto a considerar na produção de Nepomuceno é o tipo de utilização que ele faz do instrumento. À primeira vista, a observação de suas obras nos sugere uma falta de homogeneidade, mas encontramos algumas características mais freqüentes, presentes praticamente em todas as suas obras, que poderíamos considerar como constantes nesse compositor.

Verifica-se, por exemplo, uma certa regularidade quanto à divisão do material musical entre as duas mãos. A maioria das peças compõe-se de melodia com acompanhamento, onde cada um dos papéis é atribuído a uma das mãos. Em praticamente todas as peças encontramos a seguinte divisão: mão direita, melodia; mão esquerda, acompanhamento. Esse acompanhamento é geralmente constituído de baixo contra acorde ou arpejos. Esta descrição poderia sugerir uma escrita homofônica primária, mas outros fatores, que descreveremos abaixo, fazem com que o resultado não seja tão elementar. 
Exemplo (1) - 19 Mazurka (1887)

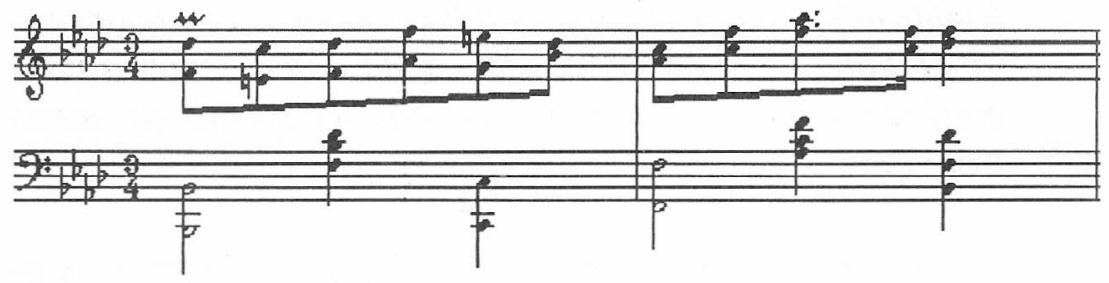

Exemplo (2) - Noturno (1904)

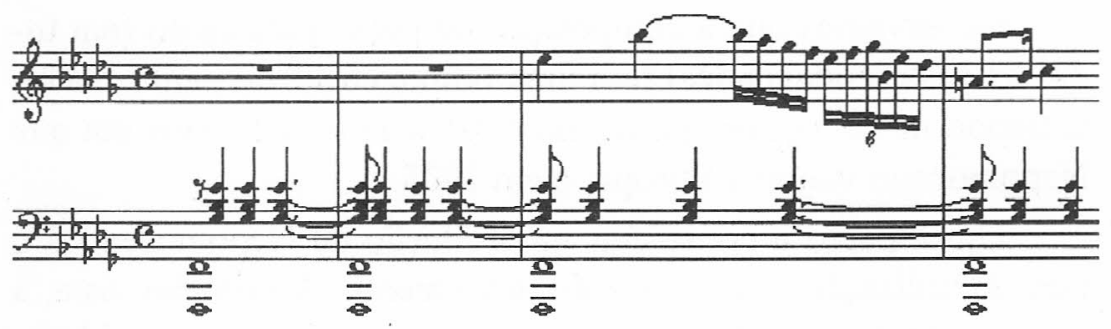

Desde as primeiras obras (Mazurkas, Une Fleur e Ninna Nanna), Nepomuceno elabora linhas contrapontísticas bastante independentes da linha melódica, criando assim um terceiro plano. Essas linhas, apresentadas ora concomitantemente à melodia, ora como imitação ou eco, vão sendo elaboradas cada vez com maior liberdade e fantasia, dando às peças uma maior profundidade $\mathrm{e}$ interesse. É interessante notar que essa escrita "em vozes" é cuidadosamente evidenciada na escrita, com a utilização de hastes em direções diferentes. 


\section{Exemplo (3) - Mazurka III (1889)}
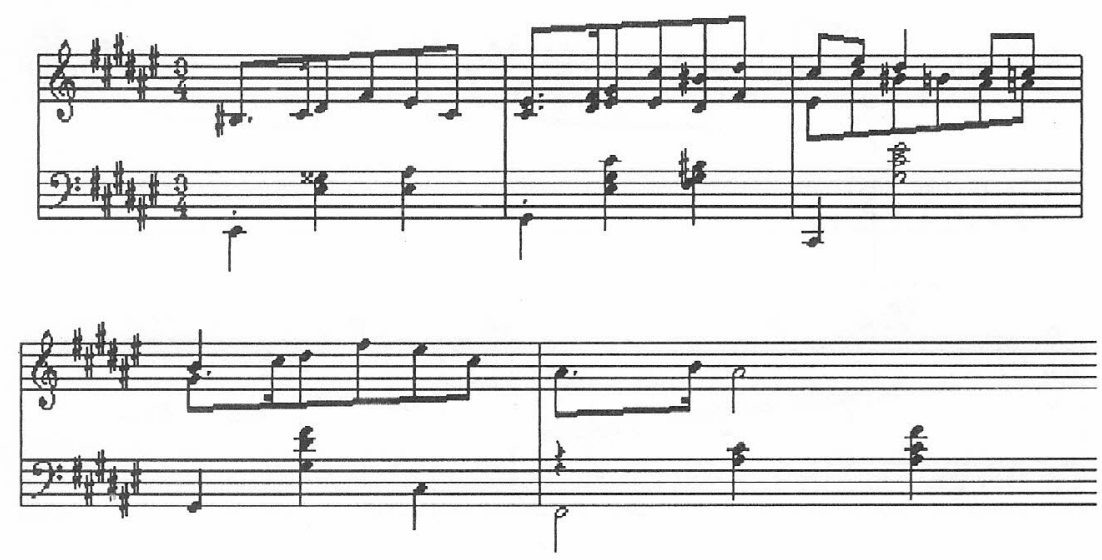

Exemplo (4) - Diálogo - n. 3 das Peças Líricas (1894)
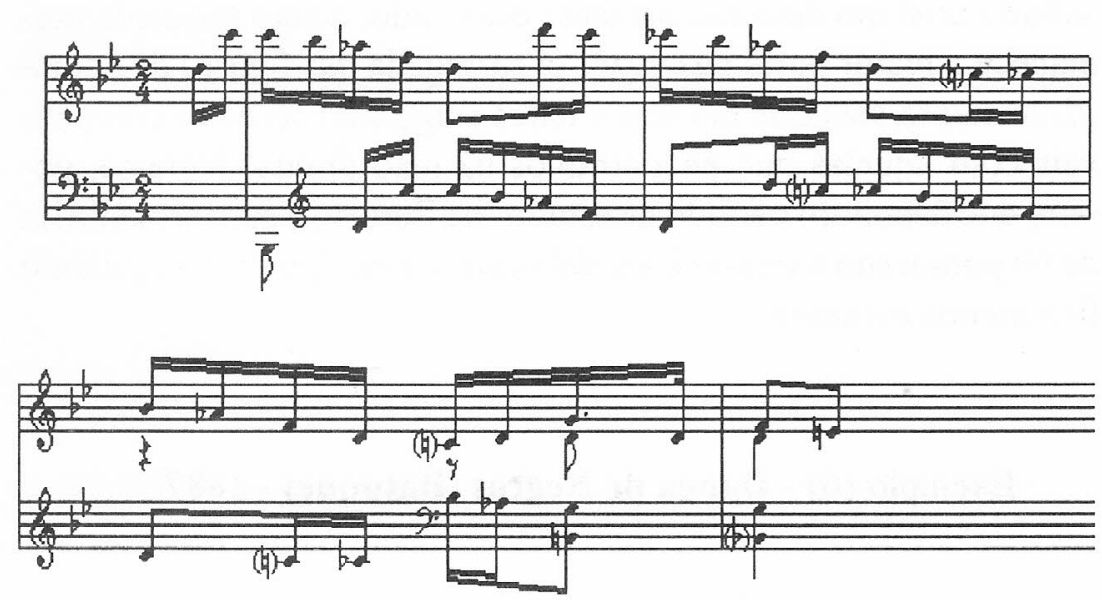

Outro recurso que encontramos utilizado por Nepomuceno é a inclusão de pequenas cadências em lugares chave do discurso. 


\section{Exemplo (5) - Devaneio (1904)}

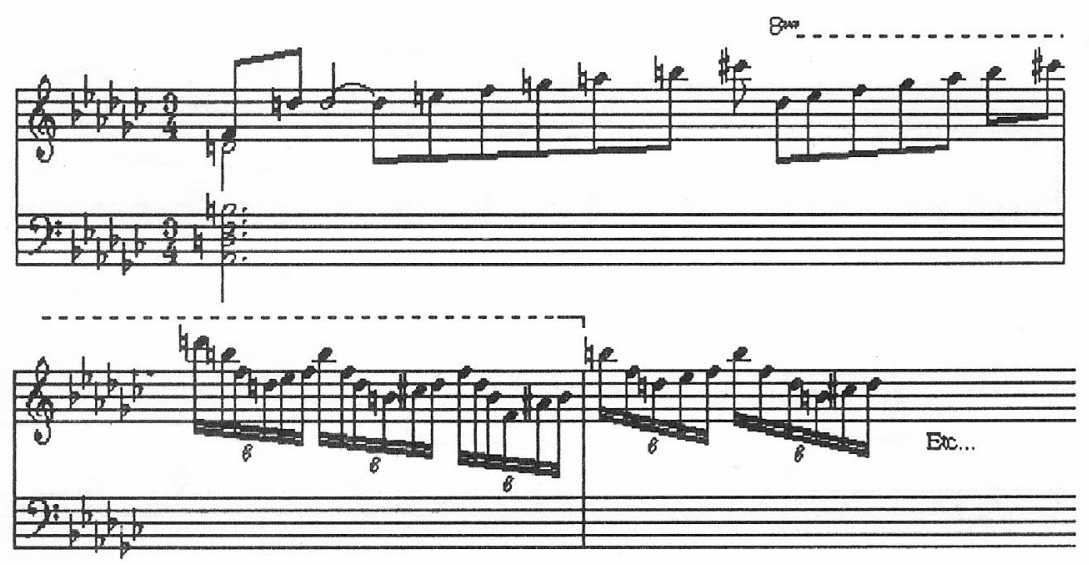

Um aspecto que chama a atenção, porém, é o uso restrito que o compositor faz da mão esquerda. Mesmo conseguindo como resultado final um discurso bastante elaborado, a mão esquerda permanece a maior parte das vezes encarregada das figuras de acompanhamento sem que lhe sejam feitas exigências técnicas compatíveis com aquelas que encontramos na mão direita. Note-se, porém, que depois do período de estudos na Europa, a escrita pianística de Nepomuceno torna-se mais elaborada e esse tipo de desequilíbrio fica menos evidente.

\section{Exemplo (6) - Dança de Negros (Batuque) - 1887}

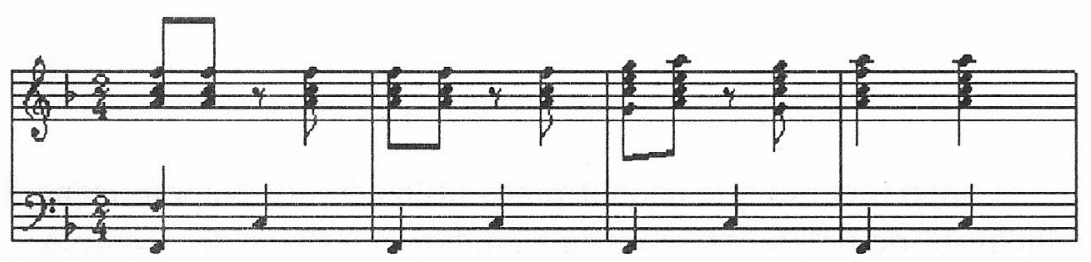


Exemplo (7) - Variações sobre um tema original (1912)
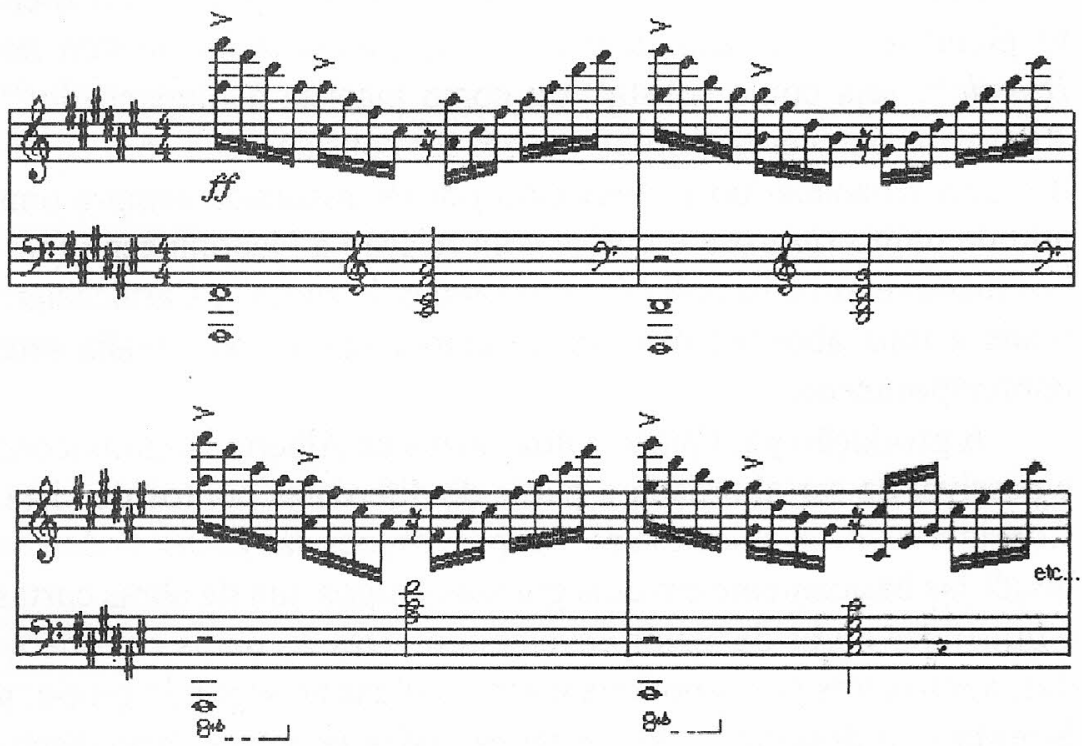

Consideramos esse fator potencialmente revelador dos recursos técnicos do próprio compositor. Imaginamos ser muito provável que a música que ele escrevia para piano, seu instrumento, se ressentisse de limitações que ele teria no domínio técnico do instrumento.

Algumas críticas de Oscar Guanabarino (1851-1937), escritas em épocas diferentes, reforçam essa hipótese. Por ocasião do concerto de estréia de Nepomuceno como pianista no Rio de Janeiro, Guanabarino publicou uma crítica na qual elogia o talento do pianista e adverte que "não lhe falta mais que tempo e continuado estudo"10. Em outra crítica, publicada quase dois anos mais tarde encontramos novamente grandes elogios à musicalidade $\mathrm{e}$ expressividade de Nepomuceno, mas duras críticas ao seu domínio técnico do instrumento. Após fazer considerações sobre a dedicação necessária para alcançar o virtuosismo no piano, sugere que ninguém conseguiria de Nepomuceno esse esforço, pois ele já teria 
descoberto "o meio de suprir pelo talento o que não quer conquistar pelo trabalho físico""1!

Cernicchiaro, ao contrário, refere-se elogiosamente ao talento pianístico de Nepomuceno em sua Storia della musica nel Brasile $^{12}$, seja como solista ${ }^{13}$ ou como pianista acompanhador ${ }^{14}$. Ambos os pareceres, porém, devem ser considerados com cuidado, pois Guanabarino é conhecido por ter assumido sempre uma atitude muito rigorosa e crítica com relação a Nepomuceno (ambos mantiveram uma polêmica nos jornais da época) e Cernicchiaro tende a uma abordagem bastante emocional quando avalia seus contemporâneos.

A produção para piano a duas mãos de Alberto Nepomuceno é passível de ser abordada a partir de diferentes pontos de vista. Considerando-se, por exemplo, as proporções das peças, podemos dividi-las basicamente em dois grandes grupos: um de obras curtas e outro das obras de maior envergadura. Das 23 obras consideradas, apenas três peças poderiam ser incluídas no segundo grupo: a Sonata e os dois ciclos de variações, todas as outras obras disponíveis são de proporções mais modestas. É importante lembrar que o Scherzo Fantastico, apesar de ter sua existência evidenciada por notícias de jornal, teve seu manuscrito extraviado, sendo então impossível avaliá-lo.

O grupo das peças curtas é formado, em sua grande maioria, de miniaturas de caráter lírico na forma de canção (os títulos escolhidos pelo autor nos dão já uma idéia bem clara da natureza das peças). A ampla dedicação de Nepomuceno a essas miniaturas (levando-se ainda em conta o fato de sua obra não ser muito volumosa), considerando não apenas a extensão e a forma dessas peças, mas também o tipo de expressão que elas manifestam, leva-nos a considerar o quanto Nepomuceno estava afinado com os grandes compositores europeus que também se dedicaram ao gênero. Esse tipo de manifestação marca a coerência dessa produção com o espírito romântico. É interessante notar o quanto a dedicação de Nepomuceno à composição de canções de câmera, a parte mais volumosa de sua produção como compositor, confirma esse espíri- 
to, a busca por esse tipo de expressão tão caracteristicamente romântica. Apenas em três peças (que serão tratadas à parte) encontramos elementos que caracterizem uma abordagem nacionalizante, fazendo com que observemos como essa prática é pouco freqüente na obra de Nepomuceno para piano a duas mãos. Outro aspecto relevante são as experiências do compositor com recursos composicionais modernos, como é o caso da bitonalidade e da escala de tons inteiros, que serão tratados adiante.

Dividimos o grupo de peças curtas em subgrupos, um grupo numeroso de miniaturas e outros subgrupos com características específicas. Entre as peças que pertencem ao grupo de miniaturas encontramos Une Fleur (1887), Ninna Nanna opus $8 n^{\circ} 1$ (1887), Folhas d'Álbum nos 1,2 e 3 (1891), o Anhelo, a Valsa e o Diálogo das Quatro Peças Líricas op. 13 (1894), a Líricas no 1 (1895), as Duas Peças op. 27, Devaneio e Improviso (1904), o Noturno op. 33 (1904), a Melodia em lá maior (s/d) e a Melodia em fá menor ( $\mathrm{s} / \mathrm{d})$. Todas estas peças seguem a estrutura de canção com a repetição idêntica da seção inicial, em alguns casos aparece uma pequena coda. A única entre estas que apresenta uma forma um pouco mais extensa é a Folha d'álbum ํo 2, onde observamos uma forma ternária ( $a a b a b a c c d c d c a b a$ coda).

Entre estas peças, a Melodia em fá menor é uma das poucas ainda não editadas. Nela observa-se a interessante alternância de compassos 2/4 e 3/4 (caso único entre as obras de Nepomuceno). Entre as peças manuscritas é a única a apresentar indicações minuciosas de dinâmica e fraseado (as Líricas nos 1 e 2 e a Pastoral não têm nenhuma indicação e a Sonata e a Valse-Impromptu apresentam pouquíssimas indicações).

O Noturno op. 33 (1904) destaca-se como uma das mais felizes realizações de Nepomuceno. Foi composto no mesmo ano que as Duas Peças op. 27 (Devaneio e Improviso), num período em que as composições para piano a duas mãos já eram raras (as composições anteriores datam de 1902 e ele só viria a escrever novamente para piano em 1915). A sessão $A$ deste Noturno apresenta longos pedais dissonantes de baixo (por exemplo fá em uma 
harmonia de mi bemol menor) e tem uma harmonização muito rica e densa, com freqüente emprego de cromatismos.

Entre as peças que destacamos do grande grupo de peças curtas, encontramos a Valse-Impromptu (1893), uma peça característica em forma ternária (Valsa e Trio, com repetição ligeiramente variada da primeira seção). Difere um pouco das peças apresentadas acima, principalmente pelo caráter mais brilhante e pela interseção freqüente de cadências.

Em Cloches de Noël, Nepomuceno utiliza-se de procedimentos que não aparecem em nenhuma de suas outras obras para piano a duas mãos. Aqui podemos observar dois momentos bem caracterizados, um deles em que verificamos um ostinato no baixo enquanto a mão direita faz um desenho imitando um carrilhão, seguido da intervenção do baixo em uma linha com caráter de recitativo, o outro momento é um coral a quatro partes, onde aparece sobrescrito um texto latino de comemoração da natividade. As duas seções não diferem apenas pela diversidade de textura $\mathrm{e}$ de tratamento instrumental, mas especialmente quanto ao ritmo: a primeira apresenta ritmo métrico e a segunda ritmo prosódico, regido pelo texto apresentado.

Exemplo (8a) - Cloches de Noël (1915) - "carrilhão"

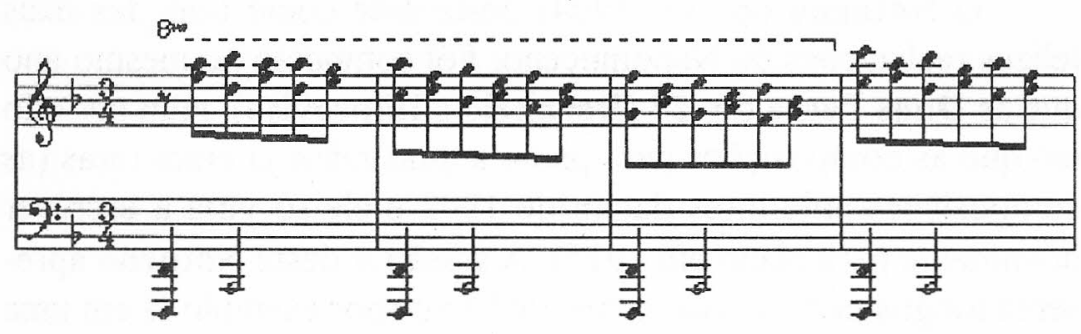


Exemplo (8b) - Cloches de Noël (1915) - "coral"

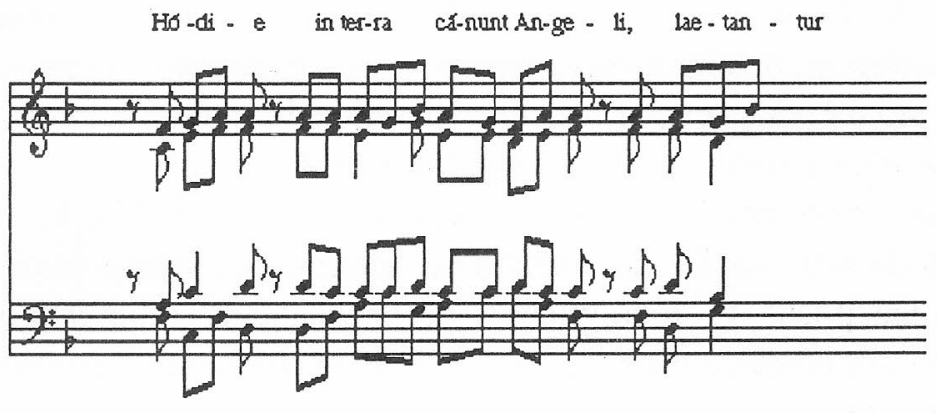

Outras duas peças que tratamos separadamente são a Pastoral (1894) e Líricas $n^{\circ} 2$ (1895). A Pastoral parece-nos ser apenas um esboço não plenamente desenvolvido pelo compositor. O principal motivo é o tipo de textura que podemos verificar nessa peça, não condizente com o tipo de resolução observável em outras peças contemporâneas de Nepomuceno. Líricas $\mathrm{n}^{0} \mathbf{2}$, por sua vez, é uma peça inacabada, na qual a escrita é interrompida no meio de uma frase.

A Suite Antique opus 11 (1893) é uma suíte de peças no estilo antigo que nos remete à Suíte Holberg op. 40 (1884) de Edward Grieg (1843-1907). A coincidência entre as duas suítes não se limita ao propósito de escrever um set de danças antigas, mas também pelo fato de as duas possuírem versões para orquestra de cordas feitas pelo próprio compositor e mesmo os movimentos serem semelhantes, na suíte de Grieg Praeludium, Sarabande, Gavotte, Air e Rigaudon e naquela de Nepomuceno Prélude, Menuet, Air e Rigaudon. Nepomuceno seguramente conheceu a obra de Grieg, se não no decorrer de seus estudos na Europa, certamente por intermédio de sua esposa, a pianista norueguesa Walborg Bang, ex-aluna de Grieg, que incluía freqüentemente obras desse compositor em seu repertório. É interessante lembrar que a Suite Antique foi composta em Bergen, Noruega (cidade natal de Grieg). Os movimentos da suíte de 
Nepomuceno seguem a linguagem e a forma tradicional das danças referidas.

As Peças infantis (Canção, Manobra Militar, Minueto e Insistência) destinam-se evidentemente à execução infantil - não se trata de peças evocativas de elementos do mundo infantil destinadas a serem executadas por instrumentistas com profundo domínio do instrumento. As quatro peças apresentam indicação cuidadosa de articulação, dinâmica e até mesmo dedilhados (indicação rara nas peças de Nepomuceno, mesmo naquelas editadas), sugerindo um objetivo didático do autor. Esse propósito é confirmado ainda pelo tratamento formal das peças, pela tessitura empregada nas mesmas (estas restringem-se ao âmbito de três oitavas) e pela harmonização simples utilizada.

Ainda entre as obras curtas encontramos outras duas peças com caráter ligeiramente diferenciado, a $1^{\mathrm{a}}$ Mazurka (1887) e a $2^{a}$ Mazurka (1889), constituídas de uma seção principal (repetida sempre de maneira idêntica, sem nenhuma modificação) intercalada com dois episódios, o segundo deles contrastante, resultando em um pequeno rondó $(A-B-A-C-A)$. É interessante notar que ambas aproximam-se muito da estrutura tradicional de Mazurka-Trio, já que o material temático de $A$ e $B$ é aparentado, quase que nos levando a considerá-lo como uma só seção dentro de uma estrutura ternária, contrastando com o $C$, mas a repetição final apenas de $A$ aproxima-as mais do rondó.

A Dança de Negros (1887), a Galhofeira, n 4 das Quatro Peças Líricas op. 13 (1894) e a Brasileira (s/d) são as únicas peças de Nepomuceno (dentro do grupo ao qual nos estamos dedicando) a apresentar um caráter nacional evidente. Nas três, Nepomuceno utiliza-se basicamente dos mesmos recursos para conseguir essa ambientação, principalmente o aspecto rítmico marcante, com uso constante de síncopas e a utilização da escala maior ou com o sétimo grau abaixado ou com o quarto grau elevado, característicos dos modos utilizados freqüentemente na música popular, principalmente do Nordeste. 
A Dança de Negros é dividida em duas grandes seções, a primeira delas (compassos 1 a 75) é constituída de uma introdução e de um tema (de caráter mais marcadamente rítmico que melódico) que vai sendo reexposto em tonalidades diferentes. Na segunda seção é apresentado novo material temático, também de caráter rítmico marcante e que recebe tratamento semelhante ao da primeira seção. Em praticamente toda a extensão da peça os baixos apresentam um pedal de primeiro e quinto graus alternados.

\section{Exemplo (9) - Dança de Negros (1887)}

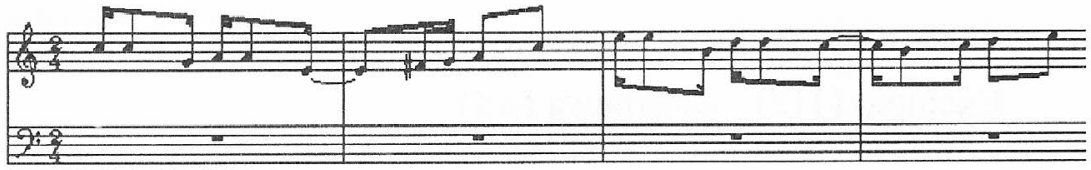

A Galhofeira difere substancialmente das outras peças da série opus 13: a expressão intimista das outras peças é substituída por uma expressão mais brilhante e mesmo harmonicamente, sua tonalidade (lá maior) é mais afastada das tonalidades das demais (fá maior, si bemol menor e si bemol maior). Assim como na Dança de Negros, aqui o elemento rítmico também é preponderante. Com relação à forma, esta peça difere um pouco daquela apresentada anteriormente. Ela também se divide em duas grandes seções: a primeira, onde o material temático é exposto em modulações sucessivas e a segunda, onde o material da primeira é reapresentado, mas em uma só tonalidade.

Exemplo (10) - Galhofeira (1894)

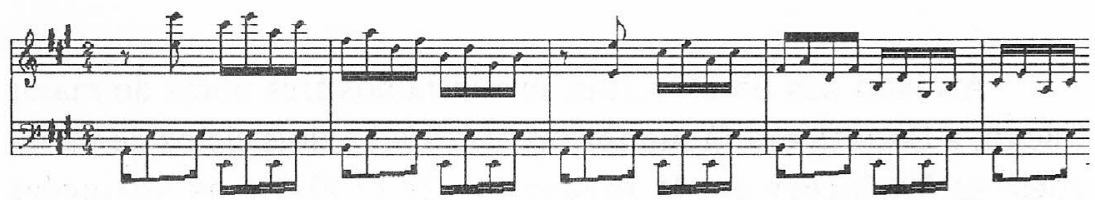

$\mathrm{Na}$ Brasileira o compositor utiliza-se de um material temático básico que vai sendo reapresentado sucessivamente recebendo a cada vez um tratamento diferente. Se comparada com as duas obras 
anteriores, percebemos que neste caso o compositor utiliza mais amplamente os recursos instrumentais.

Exemplo (11a) - Brasileira (s/d)

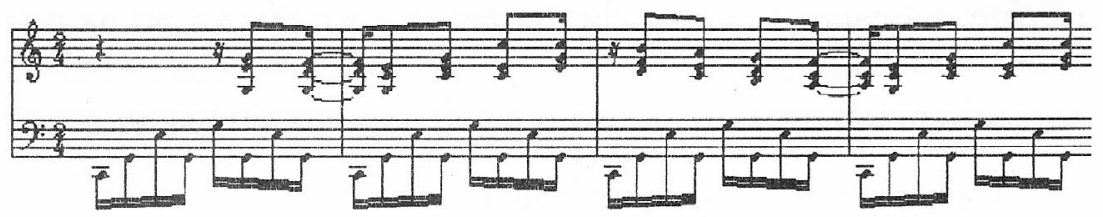

Exemplo (11b) - Brasileira (s/d)

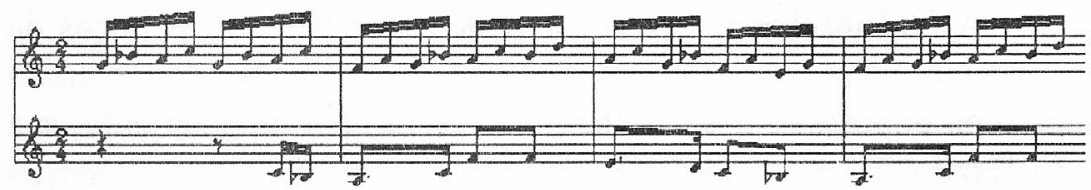

Exemplo (11c) - Brasileira (s/d)

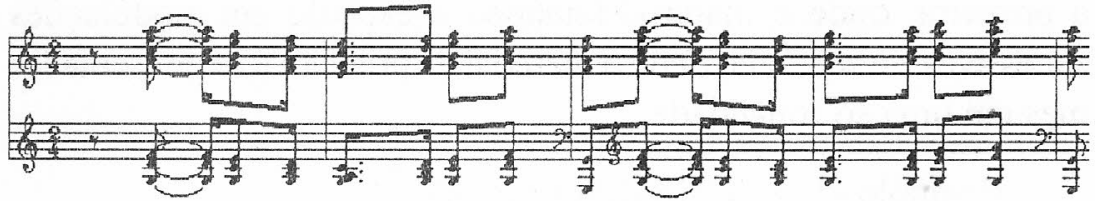

Ao lado das obras curtas, encontramos três obras de maior fôlego, a Sonata em fá menor op. $9(1894)$ e dois ciclos de variações, as Variações em lá menor op. 28 (1901) e as Variações sobre um tema original op. 29 (1902-1912). A Sonata é composta de três movimentos que obedecem à estrutura tradicional, o primeiro, Allegro con fuoco, em forma de sonata, o segundo, Andante expressivo, em forma de canção e o terceiro, Allegro con 
spirito, em forma de rondó. É provável que esta obra tenha sido escrita visando à participação em um concurso de composição ou mesmo ao cumprimento de créditos acadêmicos pelo autor durante seu período de estudos em Berlim, onde foi composta. Esta é a única incursão de Nepomuceno em uma forma mais complexa e rigorosa e parece-nos que nela o compositor não teve a mesma felicidade no domínio do métier que nas obras mais breves, esse fato pode ser justificado pela identificação do autor com obras de menor porte e pela coerência dos conteúdos musicais a serem expressados com formas mais sintéticas, fato que se verifica também com outros grandes nomes da música romântica. Trata-se, de qualquer modo, de uma obra importante, principalmente se levarmos em consideração o fato de esta ser provavelmente a primeira sonata para piano solo escrita por compositor brasileiro.

Os dois ciclos de variações constituem também obras de caráter bastante específico. O primeiro deles, Tema e variações em lá menor opus 28, foi escrito por Nepomuceno em 1901, depois de aproximadamente seis anos sem ter escrito para piano solo. É constituído de um tema e 13 variações que apresentam cada uma delas aspectos específicos da abordagem pianística. É uma peça de um certo virtuosismo e representa nesse sentido um dos poucos exemplos desse gênero na obra para piano a duas mãos de Nepomuceno. O segundo ciclo, Variações sobre um tema original opus 29 , juntamente com o op. 28 são duas das únicas quatro peças escritas para piano a duas mãos por Nepomuceno no período entre 1896 e sua morte em 1920. De acordo com as referências de data encontradas desta peça, ela teria sido iniciada 1902 e concluída em 1912, não podemos afirmar se a obra foi trabalhada permanentemente durante esse longo período ou se ela foi iniciada em 1902, abandonada e retomada para conclusão mais tarde. Apesar das semelhanças existentes entre esta obra e a anterior, esta é uma obra mais complexa tanto sob o ponto de vista musical como sob o ponto de vista pianístico, incluindo inclusive uma variação em escala de tons inteiros (nำ 8 ) e uma variação bitonal ( $\left.n^{0} 10\right)$. 
Exemplo (12) - Variações sobre um tema original - $\mathrm{n}^{0} 8$
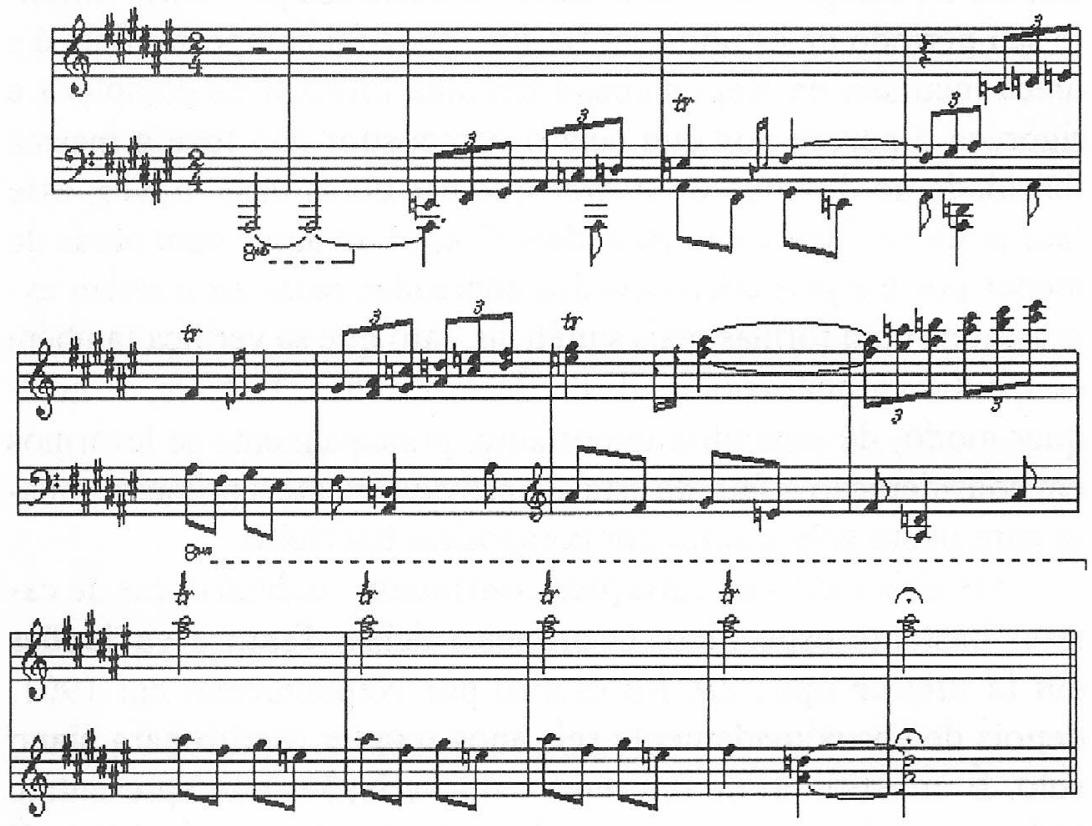

Exemplo (12a) - Variações sobre um tema original - $\mathrm{n}^{\circ} 10$

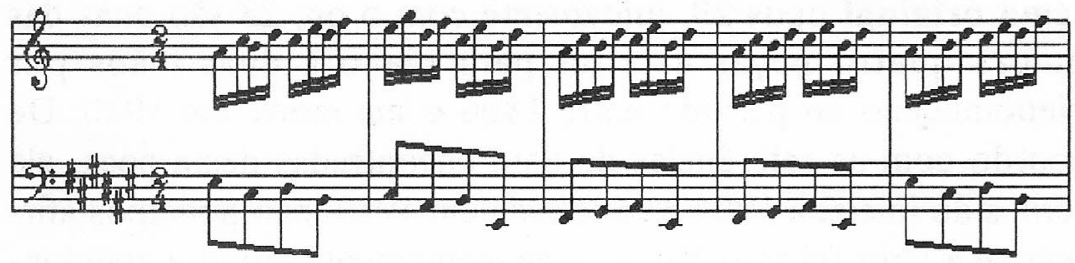

A observação da produção de Nepomuceno para piano a duas mãos como um todo leva-nos ainda à constatação de alguns pontos. O período de estudos na Europa pode ser considerado como um divisor de águas na escrita musical de Nepomuceno. As obras 
posteriores a esse período, começando pelas Folhas d'álbum, são caracterizadas pela aquisição de uma escrita mais segura, abandonando uma certa ingenuidade sensível em algumas de suas primeiras peças. De modo geral, porém, é possível verificar uma repetição sistemática de padrões rítmicos tanto em melodias como em figuras de acompanhamento, mesmo quando ocorrem alterações em outros elementos e a ocorrência de frases e seções que fogem da quadratura tradicional de múltiplos de oito compassos em grande parte das obras. Os manuscritos do compositor são muito limpos, não havendo correções, entretanto, não podemos afirmar seguramente se isso deve-se ao fato de serem cópias passadas a limpo ou se trata-se do modus operandi do compositor. Parece-nos que a segunda hipótese seja a mais provável pois em Líricas $\mathbf{n}^{0} \mathbf{2}$ podemos observar uma partitura sem correções e apresentando um resultado que condiz com o de outras peças de Nepomuceno do mesmo período, por tratar-se de uma obra inacabada, acreditamos pouco provável que se trate de uma cópia. Na Valse-Impromptu, por exemplo, verifica-se apenas uma correção de dois compassos no final da peça. Uma prática que observamos nos manuscritos de Nepomuceno é a identificação dos compassos com letras e na ocasião da reexposição do mesmo material a indicação apenas das letras referentes aos compassos a serem repetidos. Em função dessa prática, podemos observar repetições absolutamente idênticas dos trechos reexpostos, mesmo quando eles são apresentados por extenso nas edições, enquanto é freqüente observar pequenas modificações no texto quando o autor reescreve os mesmos no manuscrito.

Concluiremos este trabalho com a apresentação de uma versão parcial do catálogo revisto das obras para piano a duas mãos de Alberto Nepomuceno. Devido ao grande espaço que seria necessário para incluir o catálogo em sua versão integral, com mais detalhes sobre as obras, optamos por manter apenas os tópicos que julgamos mais importantes e característicos. A discografia apresentada não é exaustiva, servindo apenas como referência. As gravações mais importantes serão identificadas pelas seguintes abreviaturas: 
MP1 - Obra para piano de Alberto Nepomuceno. Miguel Proença, selo Arsis, 3 LP's, 1983.

MP2 - Alberto Nepomuceno. Miguel Proença, Coleção Alcoa Música Erudita Brasileira vol. 3, 1 CD, 1992.

MP3 - Obra para piano de Alberto Nepomuceno. Miguel Proença, Projeto Alberto Nepomuceno - Governo do Estado do Ceará, 2 CD's, 1993.

RS1 - Roberto Szidon, Deutsche Gramophon, LP, 1978.

RS2 - Roberto Szidon, Kuarup produções, LP, 1982.

CB - Cláudio de Brito interpreta Miguez e Nepomuceno. Cláudio de Brito, Estúdio Eldorado, LP, 1980.

AV - O alvorecer: a arte de Amaral Vieira. Amaral Vieira, Concertos, 1993.

1. 1 Mazurka em fá menor (no manuscrito consta "opus 1 no 2") local e data da composição: Rio de Janeiro, 1887. $\underline{n}^{0}$ de compassos, tonalidade e fórmula de compasso: 109 , fá menor, $3 / 4$.

estréia: 29/10/1887, Clube do Engenho Velho (RJ), pelo autor. edição: $1^{\mathrm{a}}$ edição como "Première mazurka" pela I. Bevilacqua \& Cia., RJ (depois E.S. Mangione, SP), ㄲo 2383.

data da edição: anterior a 1890.

discografia: MP1, MP3.

\section{Dança de Negros}

local e data da composição: Rio de Janeiro, 1887.

$\mathrm{n}^{\circ}$ de compassos, tonalidade e fórmula de compasso: 170 , do maior, $2 / 4$.

estréia: 08/05/1888, Clube Iracema (Fortaleza), pelo autor.

edição: da redução para piano feita pelo autor pela Casa Arthur Napoleão, RJ de no 3669 , onde a obra é apresentada como:

"A. Nepomuceno/ I İre Suite Brézilienne/ IV Batuque/ (Dansa de Negros)/ Reducção para piano pelo autôr". 
data da edição: redução do autor, entre 1893 e 1913. discografia: MP2 e MP3.

\section{Scherzo Fantastico}

local e data da composição: Rio de Janeiro, 1887.

estréia: 21/07/1887, Imperial Conservatório de Música (RJ), pelo autor.

edição: manuscrito extraviado.

discografia: nenhuma.

\section{Une Fleur}

local e data da composição: Rio de Janeiro, 1887.

$\mathrm{n}^{\circ}$ de compassos, tonalidade e fórmula de compasso: 64 , mi bemol maior, $2 / 4$.

estréia: 21/07/1887, Imperial Conservatório de Música (RJ), pelo autor.

edição: $1^{\underline{a}}$ edição I. Bevilacqua, RJ (depois E. Bevilacqua \& Cia., RJ; depois E.S. Mangione, São Paulo) nº 2382, como Une Fleur (romance).

data da edição: anterior a 1890.

discografia: MP1, RS2.

5. Ninna Nanna (editado com o opus $8 n^{0} 1$ )

local e data da composição: Rio de Janeiro, 1887.

n ${ }^{\circ}$ de compassos, tonalidade e fórmula de compasso: 93, sol maior, $3 / 8$.

estréia: 21/07/1887, Conservatório de Música (RJ), pelo autor. edição: com o título "Deux Morceaux pour piano par A. Nepo" pela editora "Carisch \& Jänichen - Editori, Milano; Edizioni Genezio Venturini, Firenze" nº 3961. Esta peça foi editada juntamente com a Mazurka em ré menor.

data da edição: não consta.

discografia: MP1, MP2, MP3. 
6. $2^{\text {a }}$ Mazurka em ré menor (opus $8 \mathrm{n}^{\circ} 2$ )

local e data da composição: Roma, 1889.

$\underline{n}^{\circ}$ de compassos, tonalidade e fórmula de compasso: 64 , ré menor, $3 / 4$.

estréia: 21/7/1887, Imperial Conservatório de Música (RJ), pelo autor.

edição: sob o título "Deux Morceaux pour piano par A. Nepo" pela editora "Carisch \& Jänichen - Editori, Milano; Edizioni Genezio Venturini, Firenze" nº 3962. Esta peça foi editada juntamente com o Ninna Nanna.

data da edição: não consta.

discografia: MP1, MP2, MP3.

\section{Folhas d'Álbum n ${ }^{\text {os }} 1,2$ e 3}

local e data da composição: Berlim, 1891.

$\mathrm{n}^{\circ}$ de compassos, tonalidade e fórmula de compasso:

$\mathrm{n}^{\mathrm{o}} 141$, lá maior, $3 / 4$.

no 2114 , ré bemol menor, $6 / 8$.

$\mathrm{n}^{\circ} 3 \quad 56$, si bemol menor, $6 / 8$.

estréia:

$\mathrm{n}^{\text {os }} 1$ e 2: 25/02/1892, Elizabeth Halls, Christiania (Oslo) - Noruega, por Walborg Bang.

$n^{0}$ 3: $\quad$ 13/09/1892 na Hochschulle, Viena - Áustria, por Theodor Leschetizky.

edição:

$\mathrm{n}^{\mathrm{o}} 1$ 1 $1^{\mathrm{a}}$ edição no suplemento da revista Arte Musical do RJ de 15/12/1891 /Bevilacqua (Editorial Mangione, SP) $\mathrm{n}^{0}$ 2858.

$\mathrm{n}^{\circ} 2 \quad 1^{\underline{a}}$ edição no suplemento da revista Renascença $\mathrm{n}^{\circ} 2 \mathrm{de}$ 1904 / Bevilacqua \& Cia. no 7713.

nํ 3 Bevilacqua \& Cia. nº 7809 . 
data da edição: $1^{\underline{a}} 1892,2^{\underline{a}} \quad 1916,3^{\underline{a}} 1917$.

observação: Existem referências às Folhas d'Álbum nos 4, 5 e 6, estas obras teriam sido compostas entre 1891 e 1892, em Berlim, mas os manuscritos nunca foram encontrados. $\mathrm{Na}$ capa de uma edição de AN constam as 6 Folhas d'Álbum com número de catálogo único para todas elas e com o título em alemão, Albumbläter (sechs klavierstücke), mas nem manuscritos, nem versões editadas dessas obras foram encontradas.

discografia: RS1, MP1, MP3.

\section{Sonata em fá menor (opus 9)}

local e data da composição: Berlim, 1893 (na partitura manuscrita consta 1894, acrescentado posteriormente por SNAC, revisor).

$\mathrm{n}^{\circ}$ de compassos, tonalidade e fórmula de compasso:

$1^{0}$ movimento - 210 , fá menor, $6 / 8$.

$2^{-}$movimento -60 , si bemol maior, $4 / 4$.

$3^{\circ}$ movimento -274 , fá menor, $6 / 8$.

estréia: 04/08/1895, Instituto Nacional de Música (RJ), pelo autor. edição: manuscrito.

discografia: MP1, MP3.

9. Suite antique opus 11

I. Prélude

II. Air

III. Menuet

IV. Rigaudon

local e data da composição: Bergen, 1893.

$\mathrm{n}^{\circ}$ de compassos, tonalidade e fórmula de compasso:

I 46 , sol menor, $4 / 4$.

II 57 , sol maior, $3 / 4$.

III 34 , sol menor, $3 / 4$. 

IV 112 (Edição Bevilacqua) ou 69 (Edição Brödrene Hals), sol menor, $4 / 4$.

estréia: 2o semestre de 1893, sarau na residência de Grieg em Bergen, Noruega.

edição: Edição Bevilacqua (viúva Bevilacqua, Rio, depois Editorial Mangione, SP) n 6146; Edição Brödrene Hals (Oslo) C.G. Röder, Leipzig nำ B.H.M. 549.

data da edição: Edição brasileira de 1907.

observações: Existe uma diferença entre final do Rigaudon da edição norueguesa e da edição brasileira da peça. A versão norueguesa conta com quase a metade do número de compassos. Todas as gravações de que dispomos seguem a versão do Rigaudon da Edição brasileira.

Transcrita em 1894 para orquestra de cordas. discografia: RS1, MP1, MP2, MP3, AV (Rigaudon).

\section{Valse-Impromptu}

local e data da composição: Bergen, 1893.

$\underline{n}^{\circ}$ de compassos, tonalidade e fórmula de compasso: 211 , réb maior, $3 / 4$.

estréia: 1893 em Bergen - Noruega, por Dagmar Walle-Hanssen (a quem foi dedicada).

edição: manuscrito. discografia: MP1, MP2, MP3.

\section{Pastoral}

local e data da composição: Paris, 1894.

$\mathrm{n}^{\circ}$ de compassos, tonalidade e fórmula de compasso: 42 , fá maior, $3 / 4$.

estréia: sem indicações.

edição: manuscrito com o título "Pastoral im Weihnacht". observações: as únicas referências que constam do catálogo de SNAC são a duração (2'00) e o fato de ser um manuscrito. Trata-se aparentemente de um esboço, provavelmente para 
uma peça a quatro mãos, na partitura está anotado "4 handig".

discografia: nenhuma.

\section{Quatro Peças Líricas opus 13}

I. Anhelo

II. Valsa

III. Diálogo

IV. Galhofeira

local e data da composição: Paris, 1894.

$\mathrm{n}^{\circ}$ de compassos, tonalidade e fórmula de compasso:

I 71 , fá maior, $4 / 4$.

II 72 , si bemol menor, $3 / 8$.

III 53, si bemol maior, $2 / 4$.

IV 187 , lá maior, $2 / 4$.

estréia: 04/08/1895 no Instituto Nacional de Música (RJ), pelo autor. edição: E. Bevilacqua \& Cia., RJ (viúva Bevilacqua depois Editorial Mangione S.A., SP) $\mathrm{n}^{\circ} 8778$.

data da edição: posterior a 1921.

discografia: RS1, MP1, MP2, MP3. Além de:

Homero Magalhães (Galhofeira) - Decca-Sinter, 1955.

Arnaldo Estrela (Valsa e Galhofeira) - Festa, 1959/76.

Christina Ortiz (Galhofeira) - Som Livre, 1976.

Denis Mirhib Akel - Tapecar/Museu Villa-Lobos, 1981.

Regina Schlochauer (Valsa) - "Brasil - Álbum de Sons e Formas", 1989.

\section{Líricas $\mathrm{n}^{0} 1$}

local e data da composição: Paris, 1895.

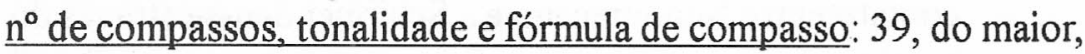
$3 / 4$.

estréia: sem indicações.

edição: manuscrito.

discografia: nenhuma. 


\section{Líricas $\mathrm{n}^{0} 2$}

local e data da composição: Paris, 1895.

$\mathrm{n}^{\circ}$ de compassos, tonalidade e fórmula de compasso: 48 (obra inacabada), do maior, $3 / 8$.

estréia: sem indicações.

edição: manuscrito.

discografia: nenhuma.

\section{Tema e Variações em lá menor opus 28}

local e data da composição: Petrópolis, 1901 (no apêndice "Registro de Músicas" da EMB aparece como 1902).

n de compassos, tonalidade e fórmula de compasso: 409 (total), lá menor, $3 / 4$.

estréia: 18/02/1905, Club dos Diários, Petrópolis, pelo autor.

edição: No manuscrito original consta op. $28 \mathrm{n}^{\circ} 1$ (catálogo de SNAC) Edição Sampaio Araújo (Arthur Napoleão), com título em francês "Théme et variations/ en La mmineur", $\mathrm{n}^{\mathrm{o}}$ 7853.

data da edição: entre 1915 e 1925.

observações: de acordo com correspondência entre Nepomuceno e a Editora Schirmer, Nepomuceno teria mandado para essa editora em 1915 os dois ciclos de variações e o Noturno opus 33, entre outras obras, para que estas fossem avaliadas para uma eventual publicação. A editora não se interessou pela edição das peças por considerá-las muito dificeis, o que seria um entrave para a sua venda. A única peça de Nepomuceno publicada pela Schirmer foi o Noturno em do maior para a mão esquerda. Cabe ressaltar que o contato entre Nepomuceno e a Schirmer deu-se através do Sr. Otto Muhm Agüero, enviado pela Schirmer ao Brasil para travar relações com as personalidades do meio musical, no intuito de ingressar no mercado local.

discografia: MP1, MP2, MP3. 


\section{Variações sobre um tema original opus 29}

local e data da composição: Petrópolis, 1902-1912.

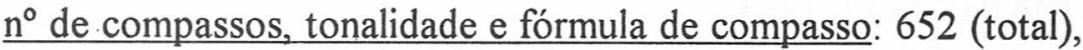
fá sustenido maior, $2 / 2$.

estréia: 26/05/1919, no Salão do Jornal do Comércio, RJ, por Irene Nogueira da Gama.

edição: Sampaio Araújo e Cia (Arthur Napoleão). com título em francês Variations/ sur un théme original, nำ 7904.

data da edição: entre 1915 e 1925.

observações: ver "observações" das Variações em lá menor. Em carta de 14/04/1919, Alfredo Oswald agradece a Nepomuceno o envio de um exemplar destas variações a ele dedicadas, citando o fato de a dedicatória ter sido omitida nessa primeira edição.

discografia: MP1, MP3.

\section{Duas peças opus 27}

I. Devaneio

II. Improviso

local e data da composição: Rio de Janeiro, 1904. $\mathrm{n}^{\circ}$ de compassos, tonalidade e fórmula de compasso:

I 52 , sol bemol maior, $3 / 4$.

II 77 , ré menor, $2 / 4$.

estréia: 18/02/1905, Club dos Diários, RJ, pelo autor.

edição: I - publicado no $17^{\circ}$ suplemento musical da revista Renascença de 07/1905; Edição E. Bevilacqua \& Cia., RJ (depois Editorial Mangione, SP) - Systema Tachygraphico Tessaro.

II - publicado no $10^{\circ}$ suplemento musical da revista Renascença de 12/1904 Edição E. Bevilacqua \& Cia., RJ (depois Editorial Mangione, SP), nº 5745 Systema Tachygraphico Tessaro.

Edição da Casa Bevilacqua -"Improviso/ Musica de Alb. Nepomuceno/ $1^{\circ}$ premio/ $1^{\circ}$ Concurso de musica da 
Renascença - Suplemento musical do $10^{\circ}$ número da revista Renascença. Endereço da editora: rua Chile, 33. data da edição: 1904. discografia: RS1, CB (Improviso), MP1, MP2, MP3.

\section{Noturno opus 33}

local e data da composição: Rio de Janeiro, 1904.

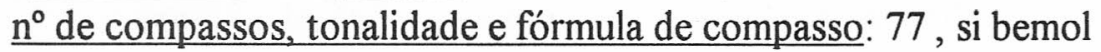
menor, $4 / 4$.

estréia: 13/01/1913, Beethoven Saal, Berlim - Alemanha, por José Vianna da Motta.

edição: Casa Arthur Napoleão (Sampaio Araújo \& Cia.) sob o título "Deux pièces pour le piano", juntamente com Cloches de Noël, $n^{\circ} 7751$. Outra edição da mesma casa - com título em português - apresenta o $\mathrm{n}^{\circ} \mathrm{AN}-169$.

data da edição: entre 1915 e 1925.

observações: ver "observações" das Variações em lá menor.

discografia: CB, MP1, MP2, MP3. Além de:

Ana Cândida - "Noturnos Brasileiros" - Documentos da Música Brasileira vol. 14 - FUNARTE, 1961/81.

\section{Cloches de Noël opus $27 \mathrm{n}^{0} 2$}

local e data da composição: Rio de Janeiro, 1915.

$\mathrm{n}^{\circ}$ de compassos, tonalidade e fórmula de compasso: 82, fá maior, $3 / 4$.

estréia: sem indicações.

edição: Edição Sampaio Araújo (Arthur Napoleão) nº 7762.

data da edição: entre 1915 e 1925.

discografia: MP1.

\section{A Brasileira}

local e data da composição: sem data.

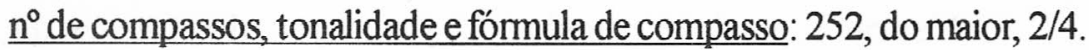


estréia: sem indicações.

edição: Sampaio Araújo (Arthur Napoleão) no 7981.

data da edição: entre 1915 e 1925.

observações: Segundo SNAC, a idéia original de Nepomuceno teria sido dedicar esta peça a Guiomar Novaes, a quem ele ofereceu o manuscrito original. Durante uma viagem de navio, a jovem pianista teria perdido esse manuscrito. Como Nepomuceno não tinha cópia deste, foi obrigado a reescrevê-lo de memória. É datada de 1919 na gravação de MP (essa mesma data aparece no catálogo da BN).

discografia: MP1, MP3. Além de:

Isabel Mourão - Discos Marcos Pereira, 1978.

\section{Melodia em lá maior}

local e data da composição: sem indicações.

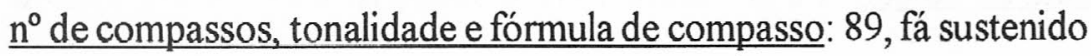
maior, $2 / 4$.

estréia: sem indicações.

edição: edição póstuma de Carlos Wehrs \& Cia. no 1443 (revisão de Barroso Neto) - impressão C.G. Röder, Leipzig (edição oficial do Instituto Nacional de Música) C.L. \& $C^{a} n^{0} 227$ data da edição: sem indicações, segundo SNAC, edição póstuma. discografia: MP1, MP2, MP3.

\section{Melodia em fá menor}

local e data da composição: sem data (EMB 1906).

$\mathrm{n}^{\circ}$ de compassos, tonalidade e fórmula de compasso: 62 , fá menor, $2 / 4$.

estréia: sem indicação.

edição: manuscrito.

discografia: MP1. 


\section{Peças Infantis}
I. Canção
II. Manobra Militar
III. Minueto
IV. Insistência

local e data da composição: sem indicações. (no verbete

Nepomuceno da EMB aparece como 1903).

$\underline{n}^{\circ}$ de compassos, tonalidade e fórmula de compasso:

I 53 , do maior, $2 / 2$.

II 74 , sol maior, $2 / 4$.

III 40 , sol maior, $3 / 4$.

IV 49 , lá menor, $3 / 4$.

estréia: sem indicação.

edição: I - Sampaio Araújo \& Cia. (Arthur Napoleão), RJ no 7887

(revisão de João Nunes - catálogo SNAC); II - no 7888 ; III- nำ 8522; IV - nํ 8515.

data da edição: I e II - entre 1915 e 1925; III e IV - entre 1925 e 1935.

discografia: MP1.

\section{NOTAS}

1. CORREAA, Sérgio Nepomuceno Alvim. Alberto Nepomuceno: catálogo geral. Rio de Janeiro: FUNARTE/Instituto de Música/Projeto Memória Musical Brasileira, 1985.

2. MARCONDES, Marcos Antônio, (Ed.). Enciclopédia da Música Brasileira: erudita, folclórica e popular. São Paulo: Art Editora Ltda., 1977. 2v.

3. BIBLIOTECA NACIONAL, UNIVERSIDADE DO CEARÁ. Catálogo da Exposição Comemorativa do Centenário de Nascimento de Alberto Nepomuceno. Rio de Janciro, Fortaleza, 1964.

4. ESCOLA NACIONAL DE MÚSICA. DA UNIVERSIDADE DO BRASIL. Catálogo da Exposição Comemorativa do Centenário de Nascimento de Alberto Nepomuceno. Rio de Janeiro, 1964.

5. Este documento encontra-se no acervo da família do compositor.

6. Documento também pertencente ao acervo da família do compositor. 
7. SALLES, Antonio. Allocução proferida por ocasião de inaugurar-se o retrato do Maestro Alberto Nepomuceno no Salão do Theatro José de Alencar. Fortaleza, 1919.

8. “(...) A sua 'dança de negros' (supomos que este é o nome) é uma peça do gênero que apontamos. (...)" (Gazeta do Norte, 11/05/1888).

9. Algumas das peças que constam sem data no catálogo SNAC, aparecem datadas em outras fontes, tal é o caso de: Peças Infantis (1903 na EMB), Melodia em fá menor, (1906 na EMB), Brasileira (1919, nas gravações de MP), devido a várias imprecisões encontradas nas datas da EMB e da não seguridade das informações encontradas nos encartes dos discos de MP, preferimos mantê-las com o registro de data ignorada, indicando a existência dessas datações apenas como referência.

10. Crítica publicada na Gazeta de Notícias a 1\%11/1885.

11. Crítica publicada em O Paiz a 24/07/1887.

12. CERNICCHIARO, Vincenzo. Storia della Musica nel Brasile: dai tempi coioniali sino ai nostri giorni (1549-1925). Milano: Riccioni, 1926.

13. op. cil. (pág. 414).

14. op. cit. (pág. 454).

Mónica Vermes é mestre em Musicologia pelo I.A. - UNESP/SP. 